\title{
Oxidatively modified phosphatidylserines on the surface of apoptotic cells are essential phagocytic 'eat-me' signals: cleavage and inhibition of phagocytosis by Lp-PLA 2
}

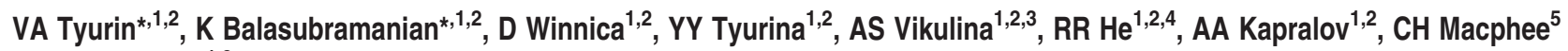 \\ and VE Kagan ${ }^{\star, 1,2}$
}

Diversified anionic phospholipids, phosphatidylserines (PS), externalized to the surface of apoptotic cells are universal phagocytic signals. However, the role of major PS metabolites, such as peroxidized species of PS (PSox) and lyso-PS, in the clearance of apoptotic cells has not been rigorously evaluated. Here, we demonstrate that $\mathrm{H}_{2} \mathrm{O}_{2}$ was equally effective in inducing apoptosis and externalization of PS in naive $\mathrm{HL} 60$ cells and in cells enriched with oxidizable polyunsaturated species of PS (supplemented with linoleic acid (LA)). Despite this, the uptake of LA-supplemented cells by RAW264.7 and THP-1 macrophages was more than an order of magnitude more effective than that of naive cells. A similar stimulation of phagocytosis was observed with LA-enriched HL60 cells and Jurkat cells triggered to apoptosis with staurosporine. This was due to the presence of PSox on the surface of apoptotic LA-supplemented cells (but not of naive cells). This enhanced phagocytosis was dependent on activation of the intrinsic apoptotic pathway, as no stimulation of phagocytosis occurred in LA-enriched cells challenged with Fas antibody. Incubation of apoptotic cells with lipoprotein-associated phospholipase $A_{2}$ (Lp-PLA $A_{2}$ ), a secreted enzyme with high specificity towards PSox, hydrolyzed peroxidized PS species in LA-supplemented cells resulting in the suppression of phagocytosis to the levels observed for naive cells. This suppression of phagocytosis by $L p-P L A_{2}$ was blocked by a selective inhibitor of Lp-PLA 2, SB-435495. Screening of possible receptor candidates revealed the ability of several PS receptors and bridging proteins to recognize both PS and PSox, albeit with diverse selectivity. We conclude that PSox is an effective phagocytic 'eat-me' signal that participates in the engulfment of cells undergoing intrinsic apoptosis.

Cell Death and Differentiation (2014) 21, 825-835; doi:10.1038/cdd.2014.1; published online 24 January 2014

Stress, infection, toxins and even normal metabolism are inevitably associated with massive cell death realized through one of the three major pathways: (i) apoptotic, (ii) autophagic and (iii) necrotic/necroptotic. ${ }^{1}$ Dead cells are cleared by professional phagocytes or neighboring cells via a series of responses directed by several chemoattracting 'find-me' signals and receptor-mediated recognition of 'eat-me' signals counterbalanced by 'don't eat me' ('self') signals exposed on the surface. ${ }^{2,3}$ The coordinated timeliness and effectiveness of the cell 'waste' disposal is crucial for the maintenance of immune tolerance and tissue homeostasis. ${ }^{4,5}$

It is now well accepted that the anionic phospholipid, phosphatidylserine (PS) - normally confined to the inner leaflet of the plasma membrane - serves as a universal 'eat-me' signal when externalized to the surface of dying cells. ${ }^{6}$ Paradoxically, however, phagocytes are known to express multiple types of receptors for clearance of dead cells raising the question about the purpose for this apparent redundancy. In attempts to resolve this conundrum, it has been suggested that in addition to PS, PS-derived metabolites that have the same phosphoryl-serine polar head, but differ in their acyl chain structure, are likely alternate ligands for these multiple receptors. For example, acyl chain-oxidized PS (PSox) has been suggested to recognize different receptors including CD36 and SR-PSox (scavenger receptor for PS and oxidized lipoproteins, CXCL16). ${ }^{7,8}$ This concept has gained

\footnotetext{
${ }^{1}$ Center for Free Radical and Antioxidant Health, University of Pittsburgh, Pittsburgh, PA, USA; ${ }^{2}$ Department of Environmental and Occupational Health, University of Pittsburgh, Pittsburgh, PA, USA; ${ }^{3}$ Department of Biophysics, MV Lomonosov Moscow State University, Moscow, Russia; ${ }^{4}$ Pharmacy College, Jinan University, Guangzhou, China and ${ }^{5}$ GlaxoSmithKline, King of Prussia, PA, USA

${ }^{*}$ Corresponding author: VA Tyurin or K Balasubramanian or V Kagan, Environmental and Occupational Health, University of Pittsburgh, 100 Technology Drive, Suite 350, Pittsburgh, PA 15260, USA. Tel: 412 6249479; Fax: 412 3832123; E-mail: vtyurin @ pitt.edu or krb84@ pitt.edu or kagan@ pitt.edu

Keywords: oxidative stress; apoptosis; phagocytosis; phosphatidylserines; oxidized phosphatidylserines; lipoprotein-associated phospholipase; inflammation Abbreviations: PS, Phosphatidylserine; PSox, oxidized PS; PC, phosphatidylcholine; PE, phosphatidylethanolamine; PI, phosphatidylinositol; PG, phosphatidylglycerol; LA, linoleic acid; LAox, oxidized linoleic acid; FFA, free fatty acid; FFAox, oxidized free fatty acid; Lyso-PS, lysophosphatidylserine; LysoPC, lysophosphatidylcholine; LysoPE, lysophosphatidylethanolamine; LysoPI, lysophosphatidylinositol; LysoPG, lysophosphatidylglycerol; DTPA, diethylenetriamine pentaacetate; BSA, bovine serum albumin; STS, staurosporine; PMA, phorbol 12-myristate 13-acetate; GAS-6, growth arrest-specific 6; Tim-4, T-cell immunoglobulin and mucin domain-containing protein 4; MFG-E8, milk fat globule-EGF factor 8 protein; BAI-1, brain-specific angiogenesis inhibitor 1; PUFA, polyunsaturated fatty acid; CMFDA, 5-chloromethylfluorescein diacetate; Lp-PLA , lipoprotein-associated phospholipase $A_{2}$; PLA $A_{1}$, phospholipase $A_{1}$; SRM, selected reaction monitoring; SIM, selected ion monitoring

Received 13.6.13; revised 03.12.13; accepted 23.12.13; Edited by S Nagata; published online 24.1.14
} 
support due to detection in apoptotic cells of different oxidized species of PS. ${ }^{8-11}$ More recently, other PS metabolites such as lyso-PS have also been identified to promote engulfment by binding G2A receptors on phagocytes. ${ }^{12,13}$

Another paradox with the concept that PS is the universal 'eat-me' signal comes from observations that, during normal physiologic activation, several cell types including macrophages, lymphocytes and endothelial cells externalize PS at levels sufficient for detection, yet escape engulfment. ${ }^{14}$ Furthermore, although both apoptotic and necrotic cells expose PS to varying degrees, ${ }^{15}$ consequences of their engulfment are starkly different. ${ }^{2}$ This raises the question as to whether cell surface appearance of PS is the single universal harbinger of phagocytosis or there are other ligands that have equally important roles as co-activators of engulfment. In particular, the essentiality of PS and PSox on the cell surface following oxidative stress-induced cell death, as well as relationships between externalized PS, PSox and lyso-PS molecular species - to the best of our knowledge - have not been resolved.

In the current work, we directly addressed these issues by detailed LC-MS analysis of PS and its oxidation/hydrolysis products. We employed human promyelocytic leukemia cell line, HL60, that has been widely used as a system to model human neutrophils ${ }^{16,17}$ and the human T lymphocytes, Jurkat cells, as two target cells. The low content of oxidizable polyunsaturated fatty acid (PUFA)-containing PS in these cells permitted us to alter the phospholipid acyl chain by culture in a medium supplemented with linoleic acid (LA). This resulted in a dramatic increase in PUFA-containing PS species that enabled a quantitative assessment of the consequence of PS oxidation - upon exposure to inducers of intrinsic apoptosis - to their phagocytic clearance by RAW264.7 and THP-1 macrophages. To ascertain the relevance of $\mathrm{PSox}$ to phagocytosis, we employed lipoprotein-associated phospholipase $A_{2}\left(L p-P L A_{2}\right)$ - an enzyme with documented selectivity towards hydrolysis of oxidatively modified (but not of non-peroxidized) PS species. ${ }^{18} \mathrm{We}$ demonstrate that presentation of PSox molecular species on the cell surface is a unique and critical signal for macrophage engulfment.

\section{Results}

LA supplementation increases the levels of oxidizable PS molecular species. To determine the relevance of oxidized PS molecular species to phagocytosis, we employed $\mathrm{H}_{2} \mathrm{O}_{2}$-induced apoptosis in HL60 cells and monitored their uptake by RAW264.7 macrophages. The neutrophil-like cell line, HL60 cells, ${ }^{16}$ is constitutively low in oxidizable LA-containing PS species and may be manipulated to incorporate LA by supplementation in the medium (Figure 1, Supplementary Figure S1). As seen from Figure 1 and Supplementary Figure S1, before LA supplementation, the major molecular species of PS in HL60 cells contained C18:0/C18:1 (sn1/sn2) (Figure 1a and Supplementary Figure S1Ba), followed by $\mathrm{C} 18: 1 / \mathrm{C} 18: 1$ and only trace amounts of C18:0/C18:2 (Figure $1 \mathrm{~b}$ and Supplementary Figure S1Bb). After LA supplementation, C18:0/C18: 2-containing PS became the prevalent molecular species (Figure $1 \mathrm{~b}$ and Supplementary Figures S1Ca and S1Cb). In addition to PS, LA was integrated into other major phospholipid classes including phosphatidylcholine (PC), phosphatidylethanolamine (PE), phosphatidylinositol (PI) and phosphatidylglycerol (PG), yielding for each molecular species corresponding to C16:0/C18:2; C18:2/C18:2, C18:1/C18:2 and C18:0/C18:2 fatty acids (data not shown).

HL60 cells containing oxidized PS are more efficiently phagocytized by macrophages. We used $\mathrm{H}_{2} \mathrm{O}_{2}$ as a common tool to induce apoptosis in HL60 cells. ${ }^{19,20}$ Naive HL60 and LA-HL60 cells were incubated with $\mathrm{H}_{2} \mathrm{O}_{2}$ to induce apoptosis (Supplementary Figure S2). At $5 \mathrm{~h}$ after addition of $\mathrm{H}_{2} \mathrm{O}_{2}$, these cells were processed in parallel for phagocytosis (Figure 2, Supplementary Figure S3) and lipidomics analysis (Figure 3, Supplementary Figures S4 and S5). Figure 2a shows an increase in phagocytosis of apoptotic HL60 targets
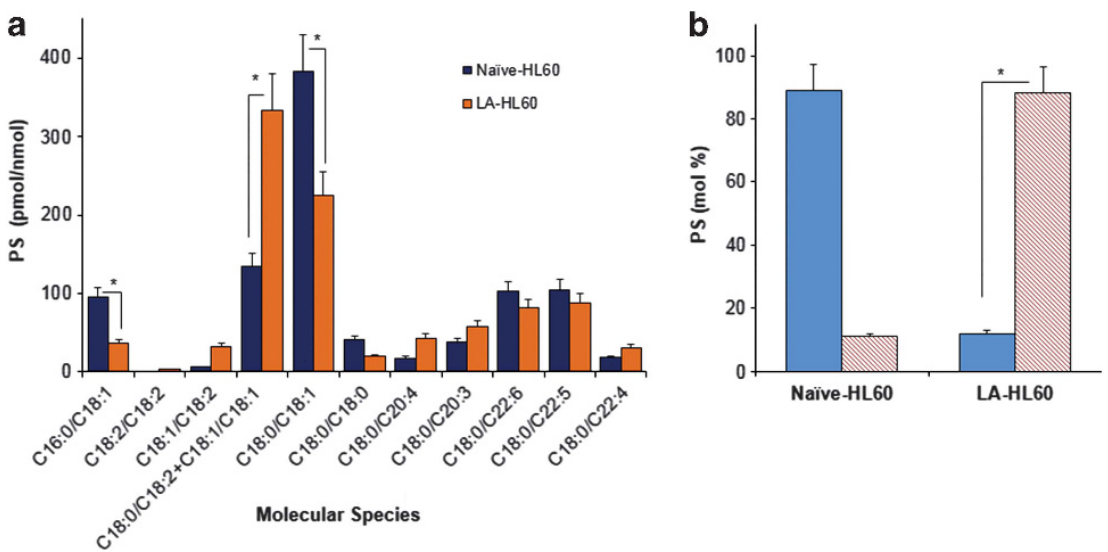

Figure 1 Assessment of oxidizable molecular species of PS in naive and LA-supplemented HL60 cells. (a) Quantitative assessment of PS molecular species (sn1/sn2) in control naive, and LA-supplemented HL60 cells. Note the increase in the content of C18:1/C18:2(m/z 784) and C18:0/C18:2+C18:1/C18:1 (m/z 786) PS molecular species and a decrease in C16:0/C18:1 (m/z 760) and C18:0/C18:1 (m/z 788) species after supplementation of cells with LA were detected. (b) Selected reaction monitoring was used to resolve the $\mathrm{m} / \mathrm{z} 786$ peak and determine the relative abundance of $\mathrm{C} 18: 1 / \mathrm{C} 18: 1$ (solid bars) and $\mathrm{C} 18: 0 / \mathrm{C} 18: 2$ (hatched bars) PS species. ${ }^{*} P<0.05, n=3$ 
A

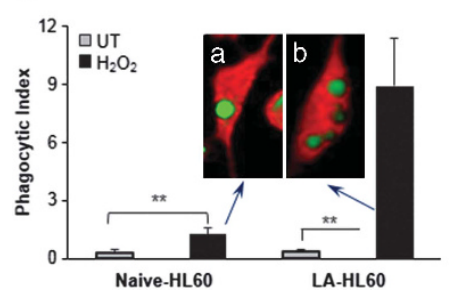

B

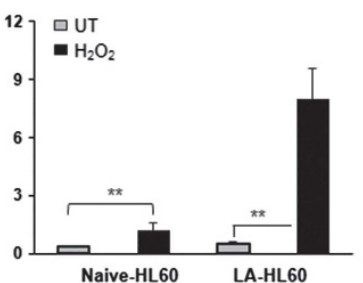

C

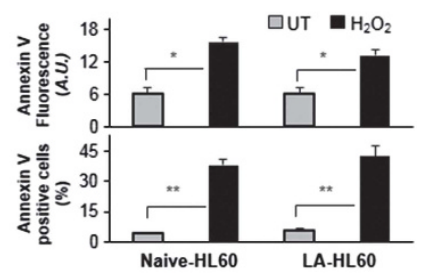

Figure 2 Apoptotic LA-HL60 cells are more efficiently phagocytized by macrophages than apoptotic naive $\mathrm{HL} 60$ cells. (A) Untreated (UT, gray bars) and $\mathrm{H}_{2} \mathrm{O}_{2}$-treated (black bars) naive-HL60 or LA-HL60 cells (targets) were labeled with CMFDA and incubated for 90 min at $37^{\circ} \mathrm{C}$ with RAW264.7 (A) or THP-1/PMA (B) macrophages. Unbound and unphagocytized targets were washed, the macrophages fixed, photographed and analyzed as described in the methods section. $n=5$. Inset $A$, photomicrographs of engulfed, apoptotic naive HL60 (a), and apoptotic LA-HL60 (b) cells. (C) Comparison of FITC-annexin V-binding intensities (top) and annexin V-positive population (lower) between naive- and LA-HL60 cells. Cells incubated with $\mathrm{H}_{2} \mathrm{O}_{2}$ for $5 \mathrm{~h}$ at $37^{\circ} \mathrm{C}$ were incubated with FITC-annexin V and assessed for change in FITC fluorescence intensities and fraction of FITC-positive cells. ${ }^{* *} P<0.01,{ }^{*} P<0.05, n=3$
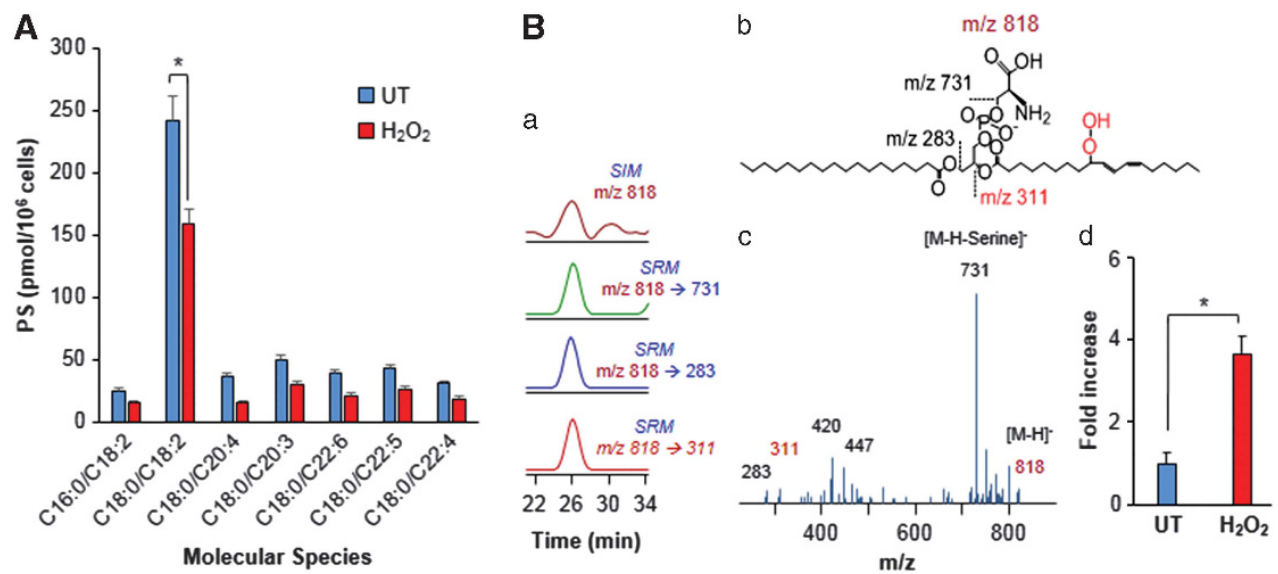

Figure 3 Lipidomics analysis of control-untreated and $\mathrm{H}_{2} \mathrm{O}_{2}$-treated LA-HL60 cells (A). Decrease in oxidizable PS molecular species in LA-supplemented HL60 cells following $\mathrm{H}_{2} \mathrm{O}_{2}$-induced apoptosis. Note: PS molecular species $\mathrm{C} 16: 0 / \mathrm{C} 18: 2, \mathrm{C} 18: 2 / \mathrm{C} 18: 2, \mathrm{C} 18: 1 / \mathrm{C} 18: 2, \mathrm{C} 18: 0 / \mathrm{C} 18: 2, \mathrm{C} 18: 0 / \mathrm{C} 20: 4 ; \mathrm{C} 18: 0 / \mathrm{C} 22: 6, \mathrm{C} 18: 0 / \mathrm{C} 22: 5$ and C18:0/C22: 4 correspond to $\mathrm{m} / \mathrm{z} 758 ; 782 ; 784 ; 786 ; 810 ; 834 ; 836$ and 838, respectively. (B) LC-MS characterization of major oxidized PS product at m/z 818 that originated from PS (C18:0/C18:2). Typical LC-MS profile (a), structure of hydroperoxy-PS species (b), $\mathrm{MS}^{2}$ spectrum (c) and fold change in $\mathrm{PS}$ ox levels after $\mathrm{H}_{2} \mathrm{O}_{2}$ treatment of LA-HL60 cells (d). Data are mean \pm S.D., ${ }^{*} P<0.05, n=3$

by RAW264.7 macrophages. A significantly more robust phagocytosis ( 7.2-fold increase in the phagocytic index and $\sim 3.5$-fold increase in phagocytosis-positive cells) was observed for the apoptotic LA-HL60 targets over naive HL60 cells (Figure $2 \mathrm{a}$, Supplementary Figure S3A). This more efficient phagocytosis was not due to increased PS externalization in apoptotic LA-HL60 versus naive HL60, as evidenced by similar FITC-annexin V-binding intensities and FITC-annexin $\mathrm{V}$-positive population in both cell types (Figure 2c). Analysis of lipids revealed a significant decrease in oxidizable PS (Figure 3A) and an approximately fourfold increase in PSox (the amount of total PSox in $\mathrm{H}_{2} \mathrm{O}_{2}$-treated cells was $130 \pm 9$ pmol per $10^{6}$ cells) in $\mathrm{H}_{2} \mathrm{O}_{2}$-treated LA-HL60 cells (Figure 3Bd). Oxygenated molecular species of PS containing two oxygens (hydroperoxy-, dihydroxy- and hydroxy-epoxy) in the C18:2-acyl chain derived from $\mathrm{C} 18$ : 0/C18:2-PS were the dominant PS oxidation products (Figure 3B). Decreases in oxidizable PC and PE were also observed (Supplementary Figure S5).

To verify that this stimulatory effect of PSox on phagocytosis is not specific for a particular macrophage cell line, we employed THP-1/phorbol 12-myristate 13-acetate (PMA) macrophages. In this case too, we found that apoptotic
LA-HL60 cells were many-fold more attractive targets over naive HL60 cells for phagocytosis by THP-1-derived macrophages (Figure 2b, Supplementary Figure S3B).

PSox formed during $\mathrm{H}_{2} \mathrm{O}_{2}$-triggered apoptosis is presented on the cell surface. We further employed LC-ESI-MS analysis (Figure 4) to assess the content of PSox on the surface of apoptotic LA-HL60 cells using two independent treatments with the following: (1) phospholipase $A_{1}\left(P L A_{1}\right)$ (in the presence of fatty acid-free bovine serum albumin (BSA)) by analyzing the production of oxidized sn2-acyl-lyso-PS and (2) Lp-PLA 2 , a phospholipase highly selective towards PSox (versus non-oxidized PS) ${ }^{18}$ with subsequent analysis of accumulated sn2-acyl-lyso-PLs. The presence of fatty acid-free BSA during the treatment with $\mathrm{PLA}_{1}$ was sufficient to bind PS hydrolysis products formed in the outer leaflet of plasma membrane as well as prevent plasma membrane damage as evidenced by $\mathrm{PI}$ negativity of the cells. This $\mathrm{PLA}_{1}$-based estimate showed the production of $24 \pm 8$ pmoles PSox per $10^{6}$ cells. Given that the PLA 1 hydrolyzed 173 pmol PS per $10^{6}$ cells (assessed by the presence of non-oxidized sn2-acyl-lyso-PS), we estimated that externalized PSox was accountable for 
$\sim 14 \pm 4 \mathrm{~mol} \%$ of the total externalized PS and for $\sim 19 \mathrm{~mol}$ $\%$ of total cell PSox.

Selective hydrolysis of externalized PSox by Lp-PLA suppresses phagocytosis of apoptotic LA-HL60 cells. The above assessments indicate that externalized PSox may represent a very potent pro-phagocytic signal. Recent studies from our laboratory have demonstrated the selectivity of $\mathrm{Lp}-\mathrm{PLA} \mathrm{A}_{2}$ for oxidized phospholipids, which includes a higher specificity for PSox. ${ }^{18}$ Hence, to further verify the role of PSox in phagocytosis, we employed Lp-PLA 2 treatment of apoptotic LA-HL60 cells and examined their phagocytosis by RAW264.7 and THP-1/PMA macrophages (Figure 5, Supplementary Figure S6). We observed a strong concentration-dependent inhibition of phagocytosis by Lp-PLA down to the levels detected with apoptotic naive HL60 cells. This suppression of phagocytosis did not occur if treatment of oxidized apoptotic LA-HL60 cells with Lp-PLA $A_{2}$ was conducted in the presence of a specific inhibitor of Lp-PLA 2 , SB-435495. 21,22 LC-MS analysis of phospholipids in Lp-PLA $A_{2}$-treated cells confirmed effective hydrolysis of PSox and accumulation of sn1-acyl-lyso-PS (Figure 6 and Supplementary Figure S7). The amount of sn1-acyl-lyso-PS formed by $L p-P L A_{2}$ treatment was $13 \pm 2$ pmol per $10^{6}$ cells $(8 \mathrm{~mol} \%$ of total cell PS, Figure 6a, Supplementary Figure S7D). As Lp-PLA 2 shows specificity towards PSox, this amount should represent externalized PSox, which is in close agreement with the results of experiments with the $\mathrm{PLA}_{1}$ treatment described above. In addition to hydrolysis of PSox and accumulation of sn1-acyl-Lyso-PS, formation of other lysophospholipids such as sn1-acyl-LysoPC, sn1-acyl-LysoPE, sn1-acyl-LysoPI and sn1-acyl-LysoPG was also detectable (Figure 6a). Notably, the contents of these lysophospholipids was low particularly in relation to the high levels of the respective parent non-hydrolyzed phospholipids. Concomitantly with lyso-PLs, several oxidized molecular species of LA (LAox) were also detected: mono-oxygenated (oxo- and hydroxy-), di-oxygenated (hydroperoxy-, dihydroxy- and hydroxy-epoxy-) and tri-oxygenated (oxo-hydroperoxy-) species with $\mathrm{m} / \mathrm{z}$ 293, 295, 311 and 325, respectively (Figure $6 \mathrm{~b}$ and Supplementary Figure S7B). No significant changes in the content of non-oxidized free fatty acids (FFAs) was observed after Lp-PLA 2 treatment (Figure 6c), thus confirming selectivity of $L p-P L A_{2}$ for oxidized PS. Notably, elevated levels of lyso-PLs were quantitatively in good correspondence with the increased amounts of LAox. Finally, accumulation of both Lyso-PS and
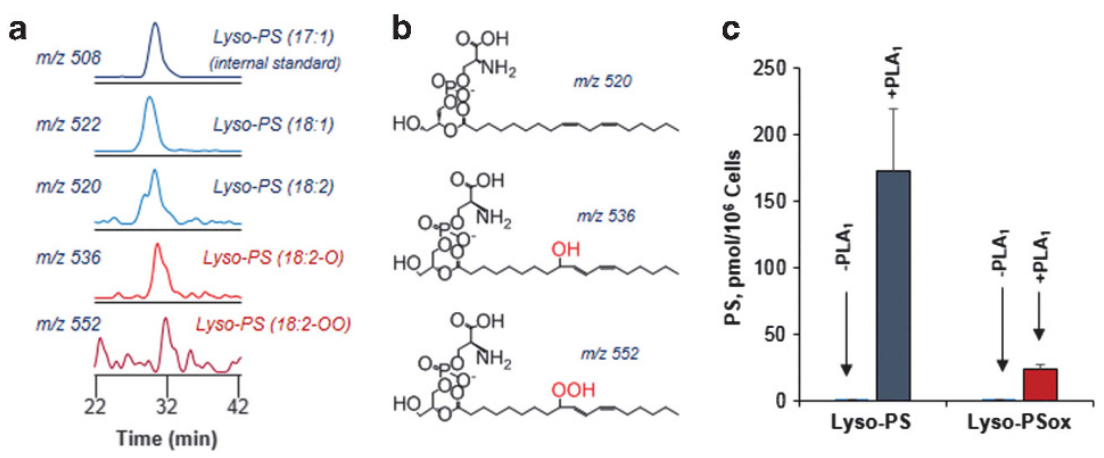

Figure 4 Externalization of PS molecular species at the outer leaflet of apoptotic LA-HL60 cells. LC-MS characterization (a) and predicted structures (b) of 2-acyl-Lysophosphatidylserine species in the BSA supernatant from PLA 1 -treated apoptotic LA-HL60 cells. (c) Quantitative assessment of outer leaflet PS and PSox in apoptotic LA-HL60 incubated in the absence or presence of $\mathrm{PLA}_{1}$ as indicated. Values are based on quantitation of corresponding 2-acyl-Lyso-PS and 2-acyl-LysoPSox formed as a result of PLA treatment. $n=3$
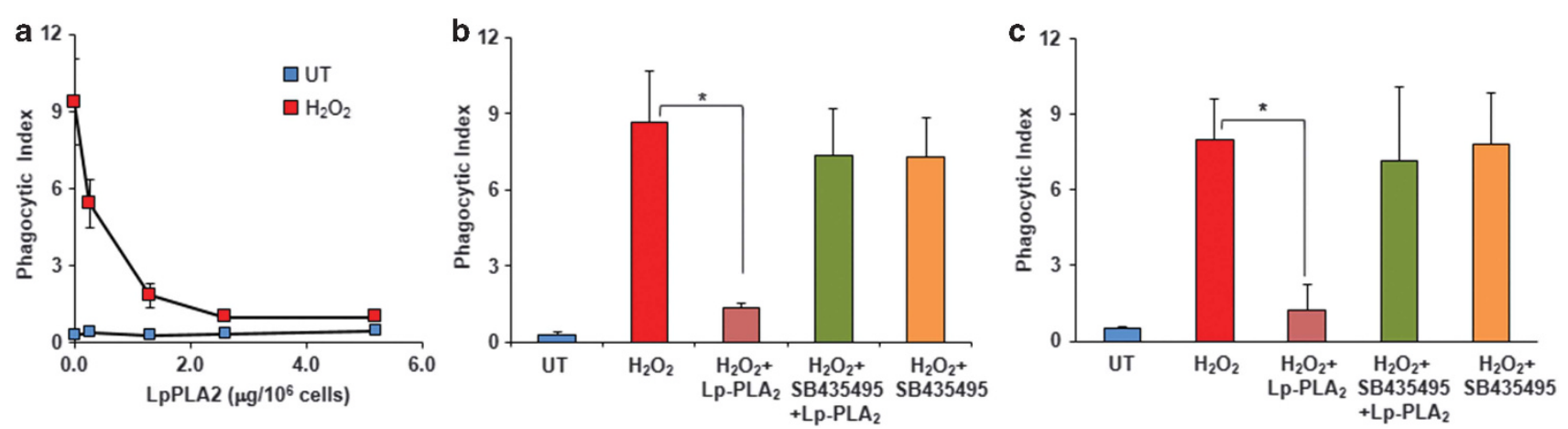

Figure 5 Lp-PLA $A_{2}$ pretreatment inhibits macrophage engulfment of apoptotic $L A-H L 60$ cells. (a) $L A-H L 60$ cells induced to undergo apoptosis with $\mathrm{H}_{2} \mathrm{O}_{2}$ were labeled with CMFDA, incubated for $40 \mathrm{~min}$ at $37^{\circ} \mathrm{C}$ with the indicated amounts of Lp-PLA 2 . The cells were then washed with HBSS to remove the enzyme and incubated with RAW264.7 to access phagocytosis. $n=3$. (b and c) Apoptotic LA-HL60 cells were incubated with recombinant human Lp-PLA $2.5 \mu \mathrm{g}$ per $10^{6}$ cells) as described above, in the absence or presence of the inhibitor SB-435495 (5 $\mu$ M) followed by assessment of phagocytosis using RAW264.7 (b) or THP-1/PMA (c) macrophages. ${ }^{*} P<0.01, n=4$ 

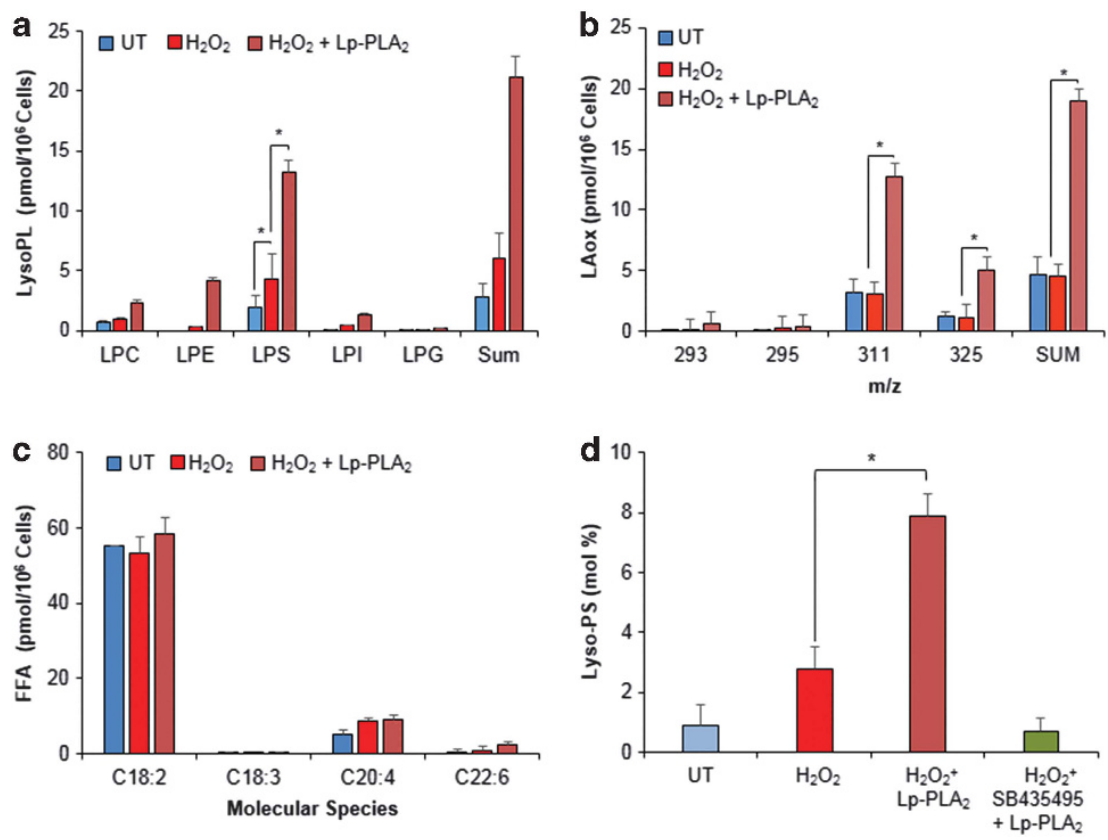

Figure 6 Lp-PLA 2 treatment of apoptotic LA-HL60 cells results in the formation of 1-acyl-lysophospholipids that correlate with release of oxygenated LA. (a) Accumulation and 1-acyl-Lyso-PLs in $\mathrm{H}_{2} \mathrm{O}_{2}$-treated LA-HL60 cells incubated with $\mathrm{Lp}-\mathrm{PLA} \mathrm{A}_{2}$ correlates with increase in oxygenated LA molecular species (b). Comparison of non-oxidized FFA between indicated treatments shows no significant differences (c). (d) Accumulation of C18: 0-lyso-PS in LA-HL60 cells treated with $\mathrm{H}_{2} \mathrm{O}_{2}$ or $\mathrm{H}_{2} \mathrm{O}_{2}+\mathrm{Lp}-\mathrm{PLA} \mathrm{A}_{2}$ in the absence and in the presence of SB35495. $n=3,{ }^{*} P<0.05$

LAox (data not shown) was reversed in the presence of the Lp-PLA 2 inhibitor SB-435495 (Figure 6d).

\section{PS oxidation and enhanced phagocytosis are attributes} of the intrinsic but not the extrinsic apoptotic pathway. To obtain further insights into the relationships between enrichment of PS with oxidizable LA-containing molecular species, apoptosis and phagocytic clearance, we employed two non-oxidant inducers of cell death - staurosporine (STS) and Fas antibody - triggering apoptosis along intrinsic and extrinsic pathways, respectively. HL60 and/or Jurkat cells were induced to undergo apoptosis using STS or Fas antibody followed by LC-MS analysis and assessment of phagocytosis. Figure 7 shows that STS-induced apoptosis in Jurkat and HL60 cells was accompanied by the accumulation of PSox (Figure 7B, and inset, Figures 7Ca and D). The amounts and molecular speciation of generated PSox were similar to those detected in $\mathrm{H}_{2} \mathrm{O}_{2}$-induced LA-HL60 cells (Figure 7B). In contrast, activation of the Fas pathway in Jurkat cells resulted in apoptosis without significant production of PSox (inset, Figure 7Cb), despite the enrichment of these cells with LA-containing PS molecular species (Figure 7A). Accordingly, we observed an enhancement of phagocytosis for STS-treated but not Fas antibody-treated cells (Figures 7C and D). Furthermore, phagocytosis experiments performed post $\mathrm{LpPLA}_{2}$ treatment again confirmed the requirement of cell surface PSox for the enhanced engulfment and uptake of target cells similar to $\mathrm{H}_{2} \mathrm{O}_{2}$-induced apoptosis in LA-HL60 cells.

Identification of putative candidate receptor/protein for PSox. Several macrophage receptors and bridging proteins have been proposed to bind PS and PSox on apoptotic cell surfaces. ${ }^{7,8,23-26}$ To determine whether these proteins show selectivity towards oxidized versus non-oxidized PS species, we performed dot blot binding studies using recombinant proteins corresponding to the extracellular domains of these receptors. As the nature of this analysis requires highly purified PSox, free from non-oxidized PS, we developed synthetic and purification strategies that ensured the isolation of PSox with more than $99.9 \%$ purity (Supplementary Figure S8). Figure 8 summarizes the results of dot blot analysis for candidate proteins binding to PS, PSox, Lyso-PS and PC (as a control for specificity). Whereas no significant binding was observed for PC and Lyso-PS, binding to PS and PSox varied between the various proteins tested. Notably, BAl-1 and GAS-6 demonstrated higher binding potency for PSox over PS. On the other hand, CXCL16, TIM-4 and CD36 showed a preference for PS over PSox, with MFG-E8 showing similar binding pattern. None of the proteins tested showed unique selectivity to PSox, in line with prior characterization of PS-binding capacities for these proteins. $^{7,8,23-26}$

\section{Discussion}

Neutrophils and macrophages are two key factors in the innate inflammatory response that begins with release of proinflammatory lipid mediators and terminates with the secretion of pro-resolution lipid mediators. The primary task of neutrophils as the first responders to infection is in situ annihilation of microbes through generation of highly reactive oxidants by NADPH oxidase and myeloperoxidase. Similarly, during sterile tissue injury, neutrophil-derived reactive intermediates promote localized apoptosis and clearance of damaged cell debris. In both cases, however, these reactive 
A a

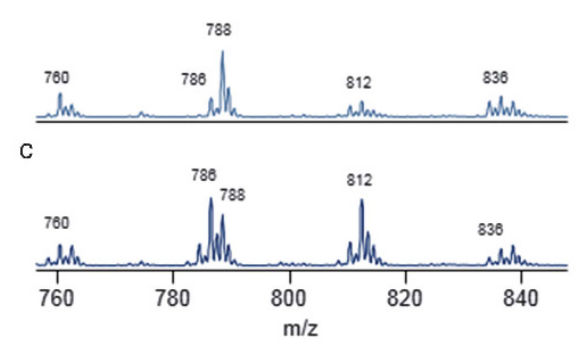

b

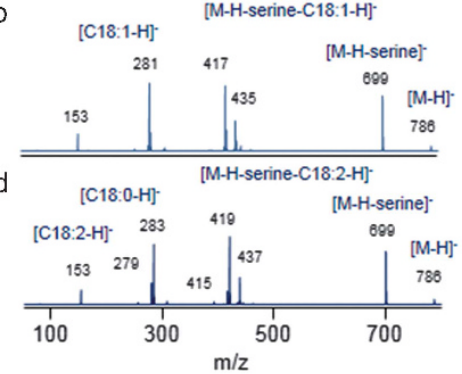

B

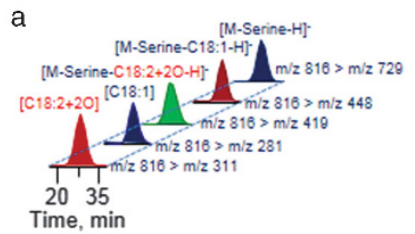

a

b

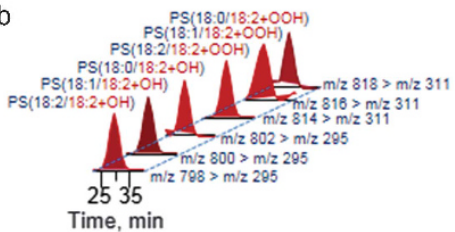

C
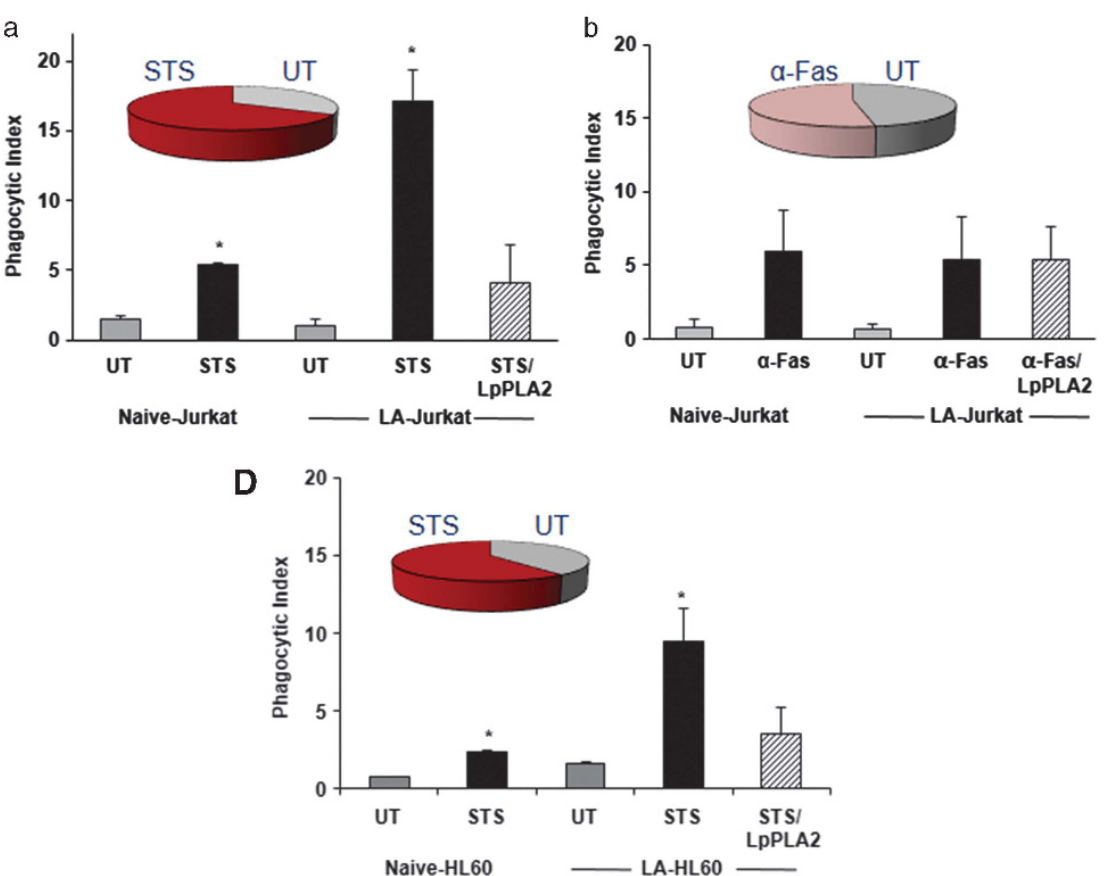

Figure 7 Lipidomics and phagocytosis analyses in STS and $\alpha$-Fas-treated LA-supplemented cells. Typical LC-MS ${ }^{1}$ and MS ${ }^{2}$ spectra of PS before (Aa) MS ${ }^{1},(\mathbf{A b}) \mathrm{MS}^{2}$ and after $(\mathbf{A c}) \mathrm{MS}^{1}$, (Ad) MS ${ }^{2}$ LA supplementation in Jurkat cells. LC-MS profiles of PSox molecular species at $\mathrm{m} / \mathrm{z} 816(18: 1 / 18: 2+20)(\mathrm{Ba})$ and species containing mono- and di-oxygenated LA (Bb) confirmed STS-induced PS oxidation in LA-supplemented Jurkat cells. (C and D) Phagocytosis of STS (Ca) and $\alpha$-Fas (Cb) treated apoptotic Jurkat cells and STS-treated HL60 cells (D). Pie charts in the inset indicate fold increase in PSox species (no change for $\alpha$-Fas) over untreated controls (UT). $n=3,{ }^{*} P<0.05$

intermediates can also inflict oxidative damage on healthy cells, including viable neutrophils in the tissue microenvironment. Uncontrolled inflammatory reactions and unwanted damage to healthy tissue are kept in check through the action of macrophages, which efficiently engulf localtissue debris and apoptotic neutrophils in an effort to redirect the inflammatory cascade towards the resolution phase. ${ }^{12}$ This hostile pro-oxidant environment should inevitably result in the accumulation of different oxidatively modifed molecules, including PSox, with potential regulatory effects on phagocytic clearance. Our previous work has emphasized pro-phagocytic effects of externalized PSox species ${ }^{9}$ and the role of NADPH oxidase in apoptotic cell clearance. ${ }^{11}$ Subsequently, Greenberg et al. ${ }^{8}$ employed myeloperoxidase/glucose oxidase oxidation in model membranes composed of oxidizable PS in palmitoyloleyl-PC (carrier) and demonstrated PSox-dependent phagocytosis of liposomes and apoptotic cells by macrophages. ${ }^{8}$ The importance of unidentified 'pro-oxidant' factors has been also noted in regulatory effects of lyso-PS on phagocytosis of neutrophils. ${ }^{12,13}$ These indications of possible essentiality of PSox in phagocytic signaling prompted us to perform quantitative LC-MS-based analyses of PSox, particularly externalized PSox, to assess its role in phagocytosis. We capitalized on the low constitutive abundance of 
a

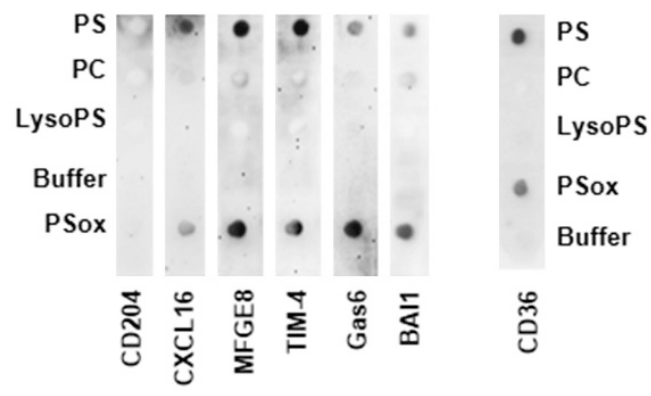

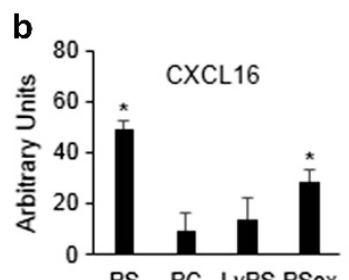
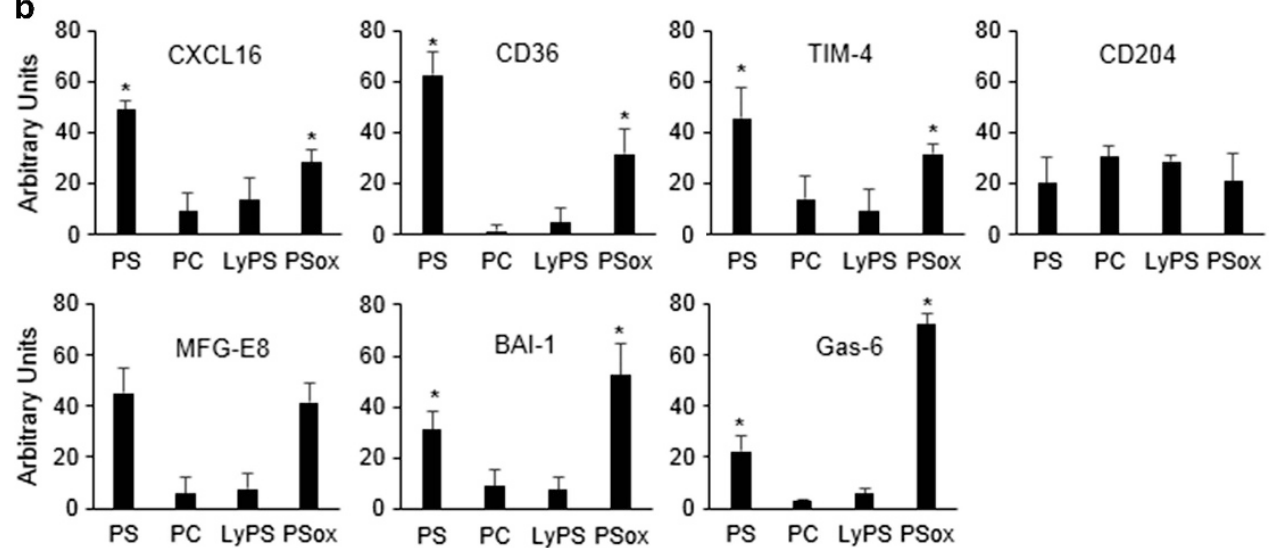

Figure 8 Dot blot binding analysis of phospholipids with macrophage receptors. Immobilized lipids $(2.7 \mathrm{nmol})$ were incubated with recombinant proteins or extracellular domains of the indicated receptors $(5.8 \mathrm{nM})$. Binding was visualized using HRP-conjugated antibody. Panel a, representative chemiluminescence image from three independent experiments. Panel $\mathbf{b}$, densitometry quantitation of binding. $n=3,{ }^{*} P<0.05$

oxidizable PS in HL60 cells to understand the importance of cell surface PSox presentation to engulfment by macrophages. We elected to use $\mathrm{H}_{2} \mathrm{O}_{2}$ to induce apoptosis ${ }^{27}$ in naive HL60 cells (low in oxidizable PS) and LA-HL60 cells (high in oxidizable PS). We were able to demonstrate that accumulation of PSox in apoptotic LA-HL60, but not naive HL60 cells, was associated with their remarkably enhanced phagocytosis by RAW264.7- and THP-1-derived macrophages. In fact, both the number of phagocytosis-positive macrophages and phagocytic index were markedly enhanced by the accumulated PSox resulting in an order of magnitude increase in the number of phagocytized LA-HL60 cells versus naive HL60 cells. According to our LC-MS-based estimates, the externalized PSox represented only a minor fraction of the total amount of PS on the surface of LA-HL60 cells. Thus, pro-phagocytic activity of PSox is approximately two orders of magnitude higher than that of PS. The accuracy of this conclusion was also confirmed by experiments with Lp-PLA demonstrating that selective removal of externalized $P S o x^{18}$ reduced phagocytosis to the levels observed for apoptotic naive-HL60 cells. This inhibitory effect of $L p-P L A_{2}$ was reversed by the selective Lp-PLA ${ }_{2}$ inhibitor, SB-435495. 22

The execution of intrinsic apoptotic program is associated with the activation of superoxide generation in mitochondria. ${ }^{28}$ Spontaneous or Mn-SOD-catalyzed dismutation of the latter yields $\mathrm{H}_{2} \mathrm{O}_{2}$. This suggests that non-oxidant pro-apoptotic agents should also trigger PS oxidation, provided the oxidizable molecular species of PS are available. Indeed, we found that a non-oxidant pro-apoptotic stimulus, STS, was also effective in inducing PS oxidation leading to enhanced phagocytic clearance of apoptotic LA-HL60 cells by RAW264.7 macrophages. Abolishment of this stimulatory effect by Lp-PLA 2 confirmed its association with externalized PSox. LA-Jurkat cells displayed a very similar pattern of apoptotic and phagocytic responses upon the STS exposure: accumulation of PS oxidation products and enhanced phagocytosis by RAW264.7 macrophages inhibitable by $\mathrm{Lp}-\mathrm{PLA}_{2}$. This is compatible with the notion that PS oxidation during intrinsic apoptosis leads to the formation of signals stimulating phagocytosis. The fact that Fas-induced apoptosis in LA-Jurkat cells caused neither PS oxidation nor enhanced phagocytosis suggests that extrinsic apoptotic mechanisms do not engage these PSox-dependent pathways to stimulate phagocytic efficiency.

The appearance of PSox on the surface of apoptotic cells, and its ability to enhance phagocytosis, might be a likely result of its interactions with one or more macrophage receptors. Whereas several receptors and bridging proteins that promote PS-dependent apoptotic cell recognition have been identified, ${ }^{7,8,23-26}$ their ability to bind PSox has not been evaluated with the notable exception of CD36 towards oxidatively truncated species of PSox. ${ }^{8}$ Our binding studies revealed that, although no unique specificity was demonstrable, PSox showed a preference for GAS-6 and BAI-1, while PS preferentially bound CXCL16, TIM-4 and CD36. Interestingly, Greenberg et al. $^{8}$ reported a higher affinity of CD36 for oxidatively truncated species of PSox. Under our experimental conditions, no truncated species of PS were 
detectable either on the surface of apoptotic cells or after PS oxidation by cytochrome $c / \mathrm{H}_{2} \mathrm{O}_{2}$. This suggests that various individual PS oxidation products may display different affinities towards receptors, thus defining the repertoire of the phagocytosis and subsequent pro-/anti-inflammatory responses. Notably, many of the binding proteins/receptors tested, including GAS-6, ${ }^{29,30}$ CD36, ${ }^{31}$ CXCL16 ${ }^{32}$ and $\mathrm{TIM}-4,{ }^{33}$ also participate in inflammation. The preferential binding of GAS-6 to PSox is particularly interesting due to reports correlating its expression with the severity of pro-inflammatory diseases including atherosclerosis. ${ }^{29,30}$ Moreover, functional mutations of the GAS-6 receptor, Mer, ${ }^{34-37}$ resulted in reduced phagocytosis and accumulation of apoptotic cells in the plaque. ${ }^{36,37}$ Although speculative, these data raise a possibility that elevated GAS- 6 expression, ${ }^{29,30}$ might contribute to opsonization of PSox-expressing apoptotic cells, thereby priming them for Mer receptordependent phagocytosis versus engagement by other receptors. On the other hand, lower GAS-6 expression and/or higher expression of MFG-E8/alphav-beta5 might shift the receptor preference, and hence post-phagocytic signaling towards anti-inflammatory pathways. ${ }^{38,39}$ In line with the marked suppressive effects of Lp-PLA2-catalyzed hydrolysis of PSox on phagocytosis of apoptotic cells, lyso-PS did not reveal any significant binding in dot blot experiments.

Overall, our data indicate that a complex regulatory system is involved in the orchestration of apoptotic cell clearance, whereby externalized PSox and its hydrolysis products may act as pro- and anti-phagocytic stimuli. For example, not only lyso-PS but also oxidatively modified species of lyso-PS (for example, formed by hydrolysis of multiply-oxygenated PSox species) as well as oxygenated FFAs can be generated from PSox by Lp-PLA $A_{2}$, which is highly expressed and secreted by activated monocyte-derived macrophages during instances of chronic inflammation. ${ }^{40-42}$ These represent a wide diversity of potential signals. Strong anti-phagocytic effects of oxygenated FFAs, for example, have been reported. ${ }^{12,43}$ Combined with possible stimulation of phagocytosis by non-oxidized lyso-PS, ${ }^{12}$ and yet to be defined signaling functions of oxygenated lyso-PS, quite complex but also remarkably diversified and flexible regulation of apoptotic cell clearance may be achieved. Thus, several unresolved questions remain, including the specific roles of different oxygen functionalities of PSox (hydroxy-, hydroperoxy-, epoxy-, oxo-) ${ }^{44}$ in the regulation of apoptotic cell clearance.

The novel observation that Lp-PLA $A_{2}$, a secreted enzyme, can interfere with phagocytosis through the hydrolysis of PSox has significant implications. A highly potent and selective inhibitor of $\mathrm{Lp}-\mathrm{PLA} \mathrm{A}_{2}$, Darapladib, is currently in Phase 3 trials for atherosclerosis. ${ }^{45,46}$ In vivo, Darapladib administration has demonstrated inhibition of Lp-PLA 2 activity in both plasma and complex atherosclerotic plaques in both humans and in a diabetic/hypercholesterolemic porcine model of atherosclerosis. In both instances, selective inhibition of Lp$\mathrm{PLA}_{2}$ by Darapladib resulted in a significant decrease in the expansion of the plaque necrotic core. ${ }^{47}$ Necrotic cores are thought to arise from the combination of apoptosis of advanced lesional macrophages and defective phagocytic clearance of the apoptotic macrophages in advanced plaques. ${ }^{48}$ Thus, given the current finding, it is tempting to speculate that the reduction in necrotic core achieved by Darapladib was at least in part due to its ability to enhance phagocytosis by preventing cleavage of a key 'eat-me' signal, PSox, through inhibition of Lp-PLA 2 . Indeed, Lp-PLA 2 appears to be well placed to modulate macrophage accumulation and function due to its ability to cleave oxidized phospholipids generating lysoPC, lysoPS and various oxidized FFAs including 9- and 13-HODE. ${ }^{18,49}$ Although still somewhat controversial, ${ }^{50}$ all three lipid products have been described as ligands for the G-protein-coupled receptor G2A, ${ }^{51,52}$ which is highly expressed in peripheral blood leukocytes and has been proposed to not only attract phagocytes to apoptotic cells but to facilitate their removal. Interestingly, lyso-PS can be generated by two distinct pathways to influence phagocytosis; by cleavage of externalized PSox, as described herein by Lp-PLA $A_{2}$, or generated intracellularly via a NADPH oxidasedependent pathway by neutrophils. ${ }^{53}$ There are currently no data implicating Lp-PLA $A_{2}$ in the latter - that is, generation of intracellular lyso-PS by activated neutrophils.

Many studies have established a direct correlation between circulating Lp-PLA 2 levels and cardiovascular disease. ${ }^{54,55}$ Whereas much of the lipidomics data in atherosclerosis research identifies elevated circulation levels of oxidized PC and $\mathrm{Lp}-\mathrm{PLA} \mathrm{A}_{2}$ as potential the key biomarkers and likely mediators of this pathology, our data provide the first line of evidence to suggest a likely negative role for the cleavage of externalized PSox in the resolution of chronic inflammation. Conceivably, this could result from a vicious cycle consisting of enhanced PLox-dependent Lp-PLA 2 secretion by resident macrophages ${ }^{40,56}$ that is coupled with reduced phagocytic capacity as a result of Lp-PLA 2 action on PSox bearing apoptotic cells. If true, inhibition of Lp-PLA $A_{2}$ may provide an approach to reverse the downsides associated with impaired phagocytosis, a dysfunctional process known to exist in several chronic inflammatory disorders, including atherosclerosis.

\section{Materials and Methods}

Cells and materials. Cell culture media, heat-inactivated fetal bovine serum (FBS), Hanks balanced salt solution (HBSS) and fluorescent cell tracker reagents were from Invitrogen (Grand Island, NY, USA), FITC-Annexin V was from Trevigen Inc. (Gaithersburg, MD, USA), Phospholipids were from Avanti Polar Lipids (Alabaster, AL, USA) and oxygenated fatty acid standards were from Cayman Chemicals (Ann Arbor, MI, USA), $\mathrm{Ca}^{2+}$-independent lipoprotein-associated phospholipase $A_{2}$ type VIIA (Lp-PLA $)$ and the Lp-PLA 2 inhibitor, SB-435495 were obtained from GlaxoSmithKline Co (Collegeville, PA, USA). Recombinant, PS-binding receptors and bridging proteins corresponding to CD36, CD204, CXCL16, growth arrest-specific 6 (GAS-6), T-cell immunoglobulin and mucin domain-containing protein 4 (Tim-4), milk fat globule-EGF factor 8 protein (MFG-E8) and brainspecific angiogenesis inhibitor 1 (BAl-1) were purchased from R\&D system (Minneapolis, MN, USA). Fas antibody (clone CH11) was from Millipore (Billerica, MA, USA). Organic solvents, phospholipase A1 (Thermomyces lanuginosus) and all other biochemical reagents were purchased from Sigma-Aldrich (St. Louis, MO, USA). Cell lines were from American Type Culture Collection and were cultured in DMEM (RAW264.5) or RPMI1640 (HL60, THP-1, Jurkat), containing 10\% FBS. THP-1 cells were differentiated to macrophages by culturing in the presence of PMA ( $40 \mathrm{pmol} / 106$ cells) for $72 \mathrm{~h}$ before experiments. Normal and reversed phase chromatography columns $(150 \times 1 \mathrm{~mm})$ were from Phenomenex, Torrance, CA, USA.

LA supplementation in HL60 cells. HL60 cells $\left(1 \times 10^{6}\right.$ cells/ml) were cultured for $16 \mathrm{~h}$ in complete medium (RPMl1640, 10\% FBS) containing LA $(100 \mathrm{nmol} / \mathrm{ml}$ medium, working concentration, $1.8 \mathrm{mM}$ in $10 \%$ fatty acid-free BSA 
made fresh). The cells were then pelleted, washed in phenol red-free RPMI1640 and used for experiments and analysis as described below.

\section{Induction of apoptosis}

$\mathrm{H}_{2} \mathrm{O}_{2}$-induced apoptosis: $\mathrm{HL} 60$ cells cultured in the absence (Naive-HL60) or presence of LA (LA-HL60) at a density of $1 \times 10^{6} \mathrm{cell} / \mathrm{s} / \mathrm{ml}$ in phenol red-free RPMl1640 medium containing $1 \%$ FBS were incubated with $100 \mu \mathrm{M} \mathrm{H}_{2} \mathrm{O}_{2}$ at $37^{\circ} \mathrm{C}$ in a $\mathrm{CO}_{2}$ incubator $\left(5 \% \mathrm{CO}_{2}\right)$. For the kinetics experiments, aliquots of control-untreated (UT) and $\mathrm{H}_{2} \mathrm{O}_{2}$-treated cells were tested for annexin V/PI binding using a BD FACS Canto flow cytometer. On the basis of these analyses, apoptosis treatment was terminated at $\sim 5 \mathrm{~h}$, following which the cells were recovered for lipidomics and phagocytosis experiments. $\mathrm{H}_{2} \mathrm{O}_{2}$-induced apoptosis of Jurkat cells was not performed because of inability to yield annexin V-positive/PI-negative cells using similar conditions.

Staurosporine induced apoptosis: Naive and LA-supplemented cells $\left(1 \times 10^{6} \mathrm{cells} / \mathrm{ml}\right.$ in phenol red-free RPMl1640 medium containing $\left.5 \% \mathrm{FBS}\right)$ were incubated with $4 \mu \mathrm{M}$ (HL60) or $300 \mathrm{nM}$ (Jurkat) STS for 4 and $2 \mathrm{~h}$, respectively. Apoptosis was assessed using flow cytometry before processing for lipidomics and phagocytosis experiments.

Fas antibody-induced apoptosis: Naive or LA-supplemented Jurkat cells $\left(1 \times 10^{6} \mathrm{cells} / \mathrm{ml}\right.$ in phenol red-free RPMl1640 medium containing 5\% FBS) were incubated for 90 min with $250 \mathrm{ng} / \mathrm{ml}$ anti-human Fas antibody (clone $\mathrm{CH}-11$ ) before flow cytometric analysis followed by lipidomics and phagocytosis evaluation. Fas antibody treatment was not undertaken with HL60 cells due to their poor sensitivity to this pathway. ${ }^{57}$

Assessment of phagocytosis. Naive and LA-supplemented cell targets $\left(1 \times 10^{6} \mathrm{cells} / \mathrm{ml}\right)$ were incubated for $30 \mathrm{~min}$ at $37^{\circ} \mathrm{C}$ with $1 \mu \mathrm{M}$ 5-chloromethylfluorescein diacetate (CMFDA). Macrophages ( $\sim 100000$ cells) were labeled under similar conditions with Hoechst $33324(500 \mathrm{ng} / \mathrm{ml})$ or $1 \mu \mathrm{M}$ CellTracker Red CMTPX. Labeled cells were washed with HBSS to remove excess dye and suspended in serum-free DMEM. Green-labeled targets were incubated for $90 \mathrm{~min}$ at $37^{\circ} \mathrm{C}$ in a $\mathrm{CO}_{2}$ incubator with macrophages (Target:Macrophage $=10: 1$ ). After this, unbound/unengulfed targets were removed by washing with HBSS and the macrophages were fixed with $2 \%$ paraformaldehyde before photomicrography using a Nikon Eclipse TE200 fluorescent microscope (Melville, NY, USA). Images were scored and the phagocytic index was calculated by multiplying the percentage of macrophages that have phagocytized by the average number of engulfed cells per macrophage. Phagocytosis was also analyzed independently using a Thermo Scientific Cellomics Celllnsight image analyzer equipped with proprietary Spot Detector software (Waltham, MA, USA). The protocol parameters were designed to count the number of CMFDA-labeled targets (greenfluorescence) enclosed within concentric rings drawn between the macrophage nuclei (blue) and the plasma membrane (red-fluorescent macrophage cytoplasm). Data were calculated and presented as the number of phagocytosis-positive cell. At least 300 fields were scored per experiment.

Treatment of cells with Lp-PLA 2 . CMFDA-labeled untreated and apoptotic cells $\left(1 \times 10^{6}\right.$ cells $\left./ \mathrm{ml}\right)$ in serum-free RPMI 1640 medium were incubated for $40 \mathrm{~min}$ at $37^{\circ} \mathrm{C}$ with the indicated amounts of $\mathrm{Lp}-\mathrm{PLA}$. The cells were then washed with HBSS before the phagocytosis assay described above. In experiments where lyso-PS and FFAs analyses were performed, fatty acid-free BSA $(5 \%)$ was included in the incubation medium. ${ }^{58}$ The cells were then tested for plasma membrane integrity (propidium iodide-negative), and total lipids extracted from both BSA supernatant and cell pellet fractions for individual LC-ESI-MS analysis.

Treatment of cells with PLA 1 . Apoptotic LA-supplemented cells were centrifuged and resuspended in RPMl1640 medium containing fatty acid-free BSA (5\%). The cells were incubated for $20 \mathrm{~min}$ at $37^{\circ} \mathrm{C}$ with PLA $13.6 \mathrm{mg} / 1 \times 10^{6}$ cell). The cells were then tested for plasma membrane integrity (propidium iodidenegative), pelleted and the lipids extracted from the BSA supernatant and pellets analyzed.

Lipid dot blot analysis. Indicated lipids $(2.7 \mathrm{nmol})$ were immobilized on PVDF membranes. The membranes were blocked with $1 \%$ ovalbumin for $60 \mathrm{~min}$ followed by incubation for $2 \mathrm{~h}$ with $5.8 \mathrm{nM}$ recombinant proteins corresponding to CD204, CXCL16, CD36, MFG-E8, Tim-4, GAS-6 and BAI-1 in 1\% ovalbumin in Tris buffered saline pH 7.2 supplemented with $150 \mu \mathrm{M} \mathrm{Ca}{ }^{2+}$ (TBS).
The membranes were incubated with HRP-conjugated antibody, washed thrice with TBS and followed by visualization using an enhanced chemiluminescent (ECL) imaging system.

PS oxidation and purification of PSox. A dispersion of PS (18:0/ $18: 2,250 \mu \mathrm{M})$ in $20 \mathrm{mM}$ HEPES buffer $\mathrm{pH} 7.4$ was oxidized using cytochrome $c / \mathrm{H}_{2} \mathrm{O}_{2} \quad(5 \mu \mathrm{M} / 100 \mu \mathrm{M})$ in the presence of $100 \mu \mathrm{M}$ diethylenetriamine pentaacetate (DTPA). After incubation for $3 \mathrm{~h}$ at $37^{\circ} \mathrm{C}$, with the addition of $100 \mu \mathrm{M} \mathrm{H}_{2} \mathrm{O}_{2}$ every $30 \mathrm{~min}$, lipids were extracted by Folch procedure, ${ }^{59}$ and PSox purified from non-oxidized PS by solid-phase extraction on a C18-E matrix. PSox was recovered from this column using acetonitrile/water/ triethylamine/acetic acid (180/20/1/1 v/v/v/v). Further purification was achieved by normal phase thin-layer chromatography using chloroform/methanol/ ammonia, (65/25/5) as the mobile phase. Purity of PSox was confirmed by LC/ESI-MS analysis.

Lipidomics analysis. Lipids were extracted by Folch procedure ${ }^{59}$ with slight modifications, under nitrogen atmosphere, at all steps. LC/ESI-MS analysis was performed on a Dionex HPLC system (utilizing the Chromeleon software), consisting of a Dionex UltiMate 3000 mobile phase pump, equipped with an UltiMate 3000 degassing unit and UltiMate 3000 autosampler (Thermo Fisher Inc., Sunnyvale, CA, USA). The Dionex HPLC system was coupled to a LXQ ion trap mass spectrometer or to a hybrid quadrupole-orbitrap mass spectrometer, Q-Exactive (Thermo Fisher Inc., San Jose, CA, USA) with the Xcalibur operating system. The instrument was operated in the negative ion mode (at a voltage differential of -3.5 to $5.0 \mathrm{kV}$, source temperature was maintained at $150^{\circ} \mathrm{C}$ ). Spectra were acquired in negative ion mode using a full range zoom $(370-1600 \mathrm{~m} / \mathrm{z}$, for PL and $200-400 \mathrm{~m} / \mathrm{z}$ for FFA) or ultra-zoom (selected ion monitoring and selected reaction monitoring (SRM)) scans. Tandem mass spectrometry $\left(\mathrm{MS}^{2}\right.$ analysis) of individual phospholipid species was used to determine the FA composition. $\mathrm{MS}^{n}$ analysis was carried out with relative collision energy ranging from 20 to $40 \%$ and with activation $q$ value at 0.25 for collision-induced dissociation and $q$ value at 0.7 for pulsed-Q dissociation technique. MS/MS analysis was performed using an isolation width of $1 \mathrm{~m} / \mathrm{z}, 5$ microscans with maximum injection time $1000 \mathrm{~ms}$. Identified lipids were quantitated using appropriate internal standards.

Normal phase column separation of phospholipids was performed on a Luna 3- $\mu \mathrm{m} \mathrm{Silica}{ }^{2} 100 \AA$ column $(150 \times 1 \mathrm{~mm}$, Phenomenex $)$. The analysis was performed using gradient solvent $A$ (hexane:propanol:water, $47: 57: 1, \mathrm{v} / \mathrm{v}$ ) and solvent B (hexane:propanol:water, 47:57:10, v/v) each containing $5 \mathrm{mM}$ ammonium acetate and $0.01 \%$ formic acid. The column was eluted at a flow rate of $0.05 \mathrm{ml} / \mathrm{min}$ as follows: $0-3 \mathrm{~min}$, linear gradient, $10-37 \%$ solvent $\mathrm{B}$; $3-12.5 \mathrm{~min}$, isocratic at $37 \%$ solvent $B ; 12.5-20$ min, linear gradient, $37-100 \%$ solvent $B ; 20-45$ min, isocratic at $100 \%$ solvent $B ; 45-60$ min, isocratic at $10 \%$ solvent $B$.

Reverse phase column separation of FFAs was performed on a Luna $3 \mu \mathrm{m} \mathrm{C1} 8^{2}$ $100 \AA$ column $(150 \times 1 \mathrm{~mm})$. The analysis was conducted using gradient solvent A (tetrahydrofuran:methanol: water:acetic acid, $25: 30: 44.9: 0.1$, v/v) and solvent B (methanol:water, $9: 1, \mathrm{v} / \mathrm{v}$ ) each containing $5 \mathrm{mM}$ ammonium acetate. The column was eluted at a flow rate of $0.05 \mathrm{ml} / \mathrm{min}$ as follows: $0-3 \mathrm{~min}$, isocratic at $50 \%$ solvent B; $3-23$ min, linear gradient, $50-98 \%$ solvent $B ; 23-40$ min, isocratic at $98 \%$ solvent B; $40-42 \mathrm{~min}$, linear gradient, $98-50 \%$ solvent $B ; 42-48 \mathrm{~min}$, isocratic at $50 \%$ solvent $B$.

Statistical analysis. The results are presented as mean \pm S.D. values from at least three experiments, and statistical analyses were performed by either paired/unpaired Student's t-test or one-way ANOVA. The statistical significance of differences was set at $P<0.05$.

\section{Conflict of Interest}

$\mathrm{CHM}$ is an employee of GlaxoSmithKline who is pursuing studies of inhibitors of $\mathrm{Lp}-\mathrm{PLA} \mathrm{A}_{2}$ (for example, Darapladib) in various clinical trials. The remaining authors declare no conflict of interest.

Acknowledgements. This work was partly supported by $\mathrm{NIH}$ (ES020693, ES021068, U19AIO68021, NS076511, P01HL114453 and CA165065) and NIOSH (OH008282) as well as a contract from GlaxoSmithKline. 
1. Green DR. The end and after: how dying cells impact the living organism. Immunity 2011 ; 35: 441-444.

2. Elliott MR, Ravichandran KS. Clearance of apoptotic cells: implications in health and disease. J Cell Biol 2010; 189: 1059-1070.

3. Rodriguez PL, Harada T, Christian DA, Pantano DA, Tsai RK, Discher DE. Minimal 'Self' peptides that inhibit phagocytic clearance and enhance delivery of nanoparticles. Science 2013; 339: 971-975.

4. Michlewska S, McColl A, Rossi AG, Megson IL, Dransfield I. Clearance of dying cells and autoimmunity. Autoimmunity 2007; 40: 267-273.

5. Tanaka M, Miyake Y. Apoptotic cell clearance and autoimmune disorder. Curr Med Chem 2007; 14: 2892-2897.

6. Fadok VA, Voelker DR, Campbell PA, Cohen JJ, Bratton DL, Henson PM. Exposure of phosphatidylserine on the surface of apoptotic lymphocytes triggers specific recognition and removal by macrophages. J Immunol 1992; 148: 2207-2216.

7. Shimaoka T, Kume N, Minami M, Hayashida K, Kataoka H, Kita T et al. Molecular cloning of a novel scavenger receptor for oxidized low density lipoprotein, SR-PSOX, on macrophages. J Biol Chem 2000; 275: 40663-40666.

8. Greenberg ME, Sun M, Zhang R, Febbraio M, Silverstein R, Hazen SL. Oxidized phosphatidylserine-CD36 interactions play an essential role in macrophage-dependent phagocytosis of apoptotic cells. J Exp Med 2006; 203: 2613-2625.

9. Tyurina YY, Kawai K, Tyurin VA, Liu SX, Kagan VE, Fabisiak JP. The plasma membrane is the site of selective phosphatidylserine oxidation during apoptosis: role of cytochrome C. Antioxid Redox Signal 2004; 6: 209-225.

10. Fabisiak JP, Tyurina YY, Tyurin VA, Kagan VE. Quantification of selective phosphatidylserine oxidation during apoptosis. Methods Mol Biol 2005; 291: 449-456.

11. Arroyo A, Modriansky M, Serinkan FB, Bello RI, Matsura T, Jiang J et al. NADPH oxidase-dependent oxidation and externalization of phosphatidylserine during apoptosis in Me2SO-differentiated HL-60 cells. Role in phagocytic clearance. J Biol Chem 2002; 277 : 49965-49975.

12. Frasch SC, Fernandez-Boyanapalli RF, Berry KZ, Leslie CC, Bonventre JV, Murphy RC et al. Signaling via macrophage G2A enhances efferocytosis of dying neutrophils by augmentation of Rac activity. J Biol Chem 2011; 286: 12108-12122.

13. Frasch SC, Bratton DL. Emerging roles for lysophosphatidylserine in resolution of inflammation. Prog Lipid Res 2012; 51: 199-207.

14. Dillon SR, Mancini M, Rosen A, Schlissel MS. Annexin V binds to viable B cells and colocalizes with a marker of lipid rafts upon B cell receptor activation. J Immunol 2000; 164: 1322-1332.

15. Borisenko GG, Matsura T, Liu SX, Tyurin VA, Jianfei J, Serinkan FB et al. Macrophage recognition of externalized phosphatidylserine and phagocytosis of apoptotic Jurkat cells-existence of a threshold. Arch Biochem Biophys 2003; 413: $41-52$.

16. Millius A, Weiner OD. Chemotaxis in neutrophil-like HL-60 cells. Methods Mol Biol 2009; 571: $167-177$

17. Mueller HW, O'Flaherty JT, Greene DG, Samuel MP, Wykle RL. 1-O-alkyl-linked glycerophospholipids of human neutrophils: distribution of arachidonate and other acyl residues in the ether-linked and diacyl species. J Lipid Res 1984; 25: 383-388.

18. Tyurin VA, Yanamala N, Tyurina YY, Klein-Seetharaman J, Macphee $\mathrm{CH}$, Kagan VE. Specificity of lipoprotein-associated phospholipase A(2) toward oxidized phosphatidylserines: liquid chromatography-electrospray ionization mass spectrometry characterization of products and computer modeling of interactions. Biochemistry 2012; 51: 9736-9750.

19. Fox S, Leitch AE, Duffin R, Haslett C, Rossi AG. Neutrophil apoptosis: relevance to the innate immune response and inflammatory disease. J Innate Immun 2010; 2: 216-227.

20. Sun L, Yau HY, Wong WY, Li RA, Huang Y, Yao X. Role of TRPM2 in $\mathrm{H}(2) \mathrm{O}(2)$-induced cell apoptosis in endothelial cells. PLOS ONE 2012; 7: e43186.

21. Blackie JA, Bloomer JC, Brown MJ, Cheng HY, Hammond B, Hickey DM et al. The identification of clinical candidate SB-480848: a potent inhibitor of lipoproteinassociated phospholipase A2. Bioorg Med Chem Lett 2003; 13: 1067-1070.

22. Blackie JA, Bloomer JC, Brown MJ, Cheng HY, Elliott RL, Hammond B et al. The discovery of SB-435495. A potent, orally active inhibitor of lipoprotein-associated phospholipase A(2) for evaluation in man. Bioorg Med Chem Lett 2002; 12: 2603-2606.

23. Kobayashi N, Karisola P, Pena-Cruz V, Dorfman DM, Jinushi M, Umetsu SE et al. TIM-1 and TIM-4 glycoproteins bind phosphatidylserine and mediate uptake of apoptotic cells. Immunity 2007; 27: 927-940

24. Nakano T, Ishimoto $\mathrm{Y}$, Kishino J, Umeda M, Inoue $\mathrm{K}$, Nagata $\mathrm{K}$ et al. Cell adhesion to phosphatidylserine mediated by a product of growth arrest-specific gene 6 . J Biol Chem 1997; 272: 29411-29414.

25. Hanayama R, Tanaka M, Miwa K, Shinohara A, Iwamatsu A, Nagata S. Identification of a factor that links apoptotic cells to phagocytes. Nature 2002; 417: 182-187.

26. Park D, Tosello-Trampont AC, Elliott MR, Lu M, Haney LB, Ma Z et al. BAl1 is an engulfment receptor for apoptotic cells upstream of the ELMO/Dock180/Rac module. Nature 2007; 450: 430-434.

27. Rollet-Labelle E, Grange MJ, Elbim C, Marquetty C, Gougerot-Pocidalo MA, Pasquier C. Hydroxyl radical as a potential intracellular mediator of polymorphonuclear neutrophil apoptosis. Free Radic Biol Med 1998; 24: 563-572.
28. Cadenas E, Davies KJ. Mitochondrial free radical generation, oxidative stress, and aging. Free Radic Biol Med 2000; 29: 222-230.

29. Hurtado B, Munoz X, Recarte-Pelz P, Garcia N, Luque A, Krupinski J et al Expression of the vitamin K-dependent proteins GAS6 and protein $S$ and the TAM receptor tyrosine kinases in human atherosclerotic carotid plaques. Thromb Haemost 2011; 105: 873-882.

30. Tjwa M, Moons L, Lutgens E. Pleiotropic role of growth arrest-specific gene 6 in atherosclerosis. Curr Opin Lipidol 2009; 20: 386-392.

31. Driscoll WS, Vaisar T, Tang J, Wilson CL, Raines EW. Macrophage ADAM17 deficiency augments CD36-dependent apoptotic cell uptake and the linked anti-inflammatory phenotype. Circ Res 2013; 113: 52-61.

32. Uza N, Nakase H, Yamamoto S, Yoshino T, Takeda Y, Ueno S et al. SR-PSOX/CXCL16 plays a critical role in the progression of colonic inflammation. Gut 2011; 60: 1494-1505.

33. Nurtanio N, Yang PC. Role of TIM-4 in innate or adaptive immune response. N Am J Med Sci 2011; 3: 217-221.

34. Lemke G, Burstyn-Cohen T. TAM receptors and the clearance of apoptotic cells. Ann N Y Acad Sci 2010; 1209: 23-29.

35. Shao WH, Zhen Y, Eisenberg RA, Cohen PL. The Mer receptor tyrosine kinase is expressed on discrete macrophage subpopulations and mainly uses Gas6 as its ligand for uptake of apoptotic cells. Clin Immunol 2009; 133: 138-144.

36. Thorp E, Cui D, Schrijvers DM, Kuriakose G, Tabas I. Mertk receptor mutation reduces efferocytosis efficiency and promotes apoptotic cell accumulation and plaque necrosis in atherosclerotic lesions of apoe $-1-$ mice. Arterioscler Thromb Vasc Biol 2008; 28 1421-1428.

37. Ait-Oufella H, Pouresmail V, Simon T, Blanc-Brude O, Kinugawa K, Merval R et al. Defective mer receptor tyrosine kinase signaling in bone marrow cells promotes apoptotic cell accumulation and accelerates atherosclerosis. Arterioscler Thromb Vasc Biol 2008; 28 : 1429-1431.

38. Lauber K, Keppeler H, Munoz LE, Koppe U, Schroder K, Yamaguchi $\mathrm{H}$ et al. Milk fat globule-EGF factor 8 mediates the enhancement of apoptotic cell clearance by glucocorticoids. Cell Death Differ 2013; 20: 1230-1240.

39. Matsuda A, Jacob A, Wu R, Aziz M, Yang WL, Matsutani T et al. Novel therapeutic targets for sepsis: regulation of exaggerated inflammatory responses. J Nippon Med Sch 2012; 79: $4-18$.

40. Macphee $\mathrm{CH}$, Nelson JJ, Zalewski A. Lipoprotein-associated phospholipase A2 as a target of therapy. Curr Opin Lipidol 2005; 16: 442-446.

41. Chauffe RJ, Wilensky RL, Mohler ER III. Recent developments with lipoprotein-associated phospholipase A2 inhibitors. Curr Atheroscler Rep 2010; 12: 43-47.

42. Kolodgie FD, Burke AP, Skorija KS, Ladich E, Kutys R, Makuria AT et al. Lipoprotein-associated phospholipase A2 protein expression in the natural progression of human coronary atherosclerosis. Arterioscler Thromb Vasc Biol 2006; 26: 2523-2529.

43. Vangaveti V, Baune BT, Kennedy RL. Hydroxyoctadecadienoic acids: novel regulators of macrophage differentiation and atherogenesis. Ther Adv Endocrinol Metab 2010; 1 : $51-60$.

44. Domingues MR, Reis A, Domingues P. Mass spectrometry analysis of oxidized phospholipids. Chem Phys Lipids 2008; 156: 1-12.

45. O'Donoghue ML, Braunwald E, White HD, Serruys P, Steg PG, Hochman J et al. Study design and rationale for the Stabilization of pLaques usIng Darapladib-Thrombolysis in Myocardial Infarction (SOLID-TIMI 52) trial in patients after an acute coronary syndrome. Am Heart J 2011; 162: 613-619.

46. White $\mathrm{H}$, Held C, Stewart R, Watson D, Harrington R, Budaj A et al. Study design and rationale for the clinical outcomes of the STABILITY Trial (STabilization of Atherosclerotic plaque By Initiation of darapLadlb TherapY) comparing darapladib versus placebo in patients with coronary heart disease. Am Heart $J$ 2010; 160: 655-661.

47. Wilensky RL, Shi Y, Mohler ER III, Hamamdzic D, Burgert ME, Li J et al. Inhibition of lipoprotein-associated phospholipase $\mathrm{A} 2$ reduces complex coronary atherosclerotic plaque development. Nat Med 2008; 14: 1059-1066.

48. Tabas I. Macrophage death and defective inflammation resolution in atherosclerosis. Nat Rev Immunol 2010; 10: 36-46.

49. Wilensky RL, Macphee $\mathrm{CH}$. Lipoprotein-associated phospholipase $\mathrm{A}(2)$ and atherosclerosis. Curr Opin Lipidol 2009; 20: 415-420.

50. Bercher M, Hanson B, van SC, Wu K, Ng GY, Lee PH. Agonists of the orphan human G2A receptor identified from inducible G2A expression and beta-lactamase reporter screen. Assay Drug Dev Technol 2009; 7: 133-142.

51. Peter C, Waibel M, Radu CG, Yang LV, Witte ON, Schulze-Osthoff $K$ et al. Migration to apoptotic 'find-me' signals is mediated via the phagocyte receptor G2A. J Biol Chem 2008; 283: 5296-5305.

52. Obinata H, Izumi T. G2A as a receptor for oxidized free fatty acids. Prostaglandins Other Lipid Mediat 2009; 89: 66-72.

53. Frasch SC, Fernandez-Boyanapalli RF, Berry KA, Murphy RC, Leslie CC, Nick JA et al. Neutrophils regulate tissue neutrophilia in inflammation via the oxidant-modified lipid lysophosphatidylserine. J Biol Chem 2013; 288: 4583-4593.

54. Tsimikas S, Willeit J, Knoflach M, Mayr M, Egger G, Notdurfter $\mathrm{M}$ et al. Lipoprotein-associated phospholipase A2 activity, ferritin levels, metabolic syndrome, 
and 10-year cardiovascular and non-cardiovascular mortality: results from the Bruneck study. Eur Heart J 2009; 30: 107-115.

55. Thompson A, Gao P, Orfei L, Watson S, Di AE, Kaptoge S et al. Lipoprotein-associated phospholipase $\mathrm{A}(2)$ and risk of coronary disease, stroke, and mortality: collaborative analysis of 32 prospective studies. Lancet 2010; 375: 1536-1544.

56. Rosenson RS, Stafforini DM. Modulation of oxidative stress, inflammation, and atherosclerosis by lipoprotein-associated phospholipase A2. J Lipid Res 2012; 53: 1767-1782.
57. Vondracek J, Sheard MA, Krejci P, Minksova K, Hofmanova J, Kozubik A. Modulation of death receptor-mediated apoptosis in differentiating human myeloid leukemia HL-60 cells. J Leukoc Biol 2001; 69: 794-802.

58. Nilsson OS, Dallner G. Transverse asymmetry of phospholipids in subcellular membranes of rat liver. Biochim Biophys Acta 1977; 464: 453-458.

59. Folch J, Sloane Stanley GH. A simple method for the isolation and purification of total lipides from animal tissues. J Biol Chem 1957; 226: 497-509.

Supplementary Information accompanies this paper on Cell Death and Differentiation website (http://www.nature.com/cdd) 